\title{
Expression of Aspergillus niger glucose oxidase in Pichia pastoris and its antimicrobial activity against Agrobacterium and Escherichia coli
}

\author{
Yonggang Wang ${ }^{\text {Corresp., Equal first author, 1, 2, Jiangqin Wang }}{ }^{\text {Equal first author, 1, 2, Feifan Leng }}{ }^{1,2}$, Jianzhong Ma ${ }^{\text {Corresp., } 1,2}$, Alnoor Bagad \\ ${ }^{1}$ School of Life Science and Engineering, Lanzhou University of Technology, Lanzhou, Gansu, China \\ ${ }^{2}$ Key Laboratory of Drug Screening and Deep Processing for Traditional Chinese and Tibetan Medicine of Gansu Province, Lanzhou University of \\ Technology, Lanzhou, Gansu, China \\ Corresponding Authors: Yonggang Wang, Jianzhong Ma \\ Email address: wangyg@lut.cn, majz@lut.cn
}

The gene encoding glucose oxidase from Aspergillus niger ZM-8 was cloned and transferred to Pichia pastoris GS115, a transgenic strain P. pastoris GS115-His-GOD constructed. The growth curve of $P$. pastoris GS115-His-GOD was consistent with that of Pichia pastoris GS115-pPIC9K under non-induced culture conditions. Under methanol induction conditions, the growth of the GOD-transgenic strain was significantly lowered than $P$. pastoris GS115-pPIC9K with the induced-culture time increase, and the optical densities of GOD-transgenic strain reached one-third of that of the P. pastoris GS115pPIC9K at $51 \mathrm{~h}$. The activity of glucose oxidase in the cell-free supernatant, the supernatant of cell lysate, and the precipitation of cell lysate was $14.3 \mathrm{U} / \mathrm{mL}, 18.2 \mathrm{U} / \mathrm{mL}$ and $0.48 \mathrm{U} / \mathrm{mL}$, respectively. The specific activity of glucose oxidase was $8.3 \mathrm{U} / \mathrm{mg}, 6.52$ $\mathrm{U} / \mathrm{mg}$ and $0.73 \mathrm{U} / \mathrm{mg}$, respectively. The concentration of hydrogen peroxide formed by glucose oxidase from supernatant of the fermentation medium, the supernatant of the cell lysate, and the precipitation of cell lysate catalyzing $0.2 \mathrm{M}$ glucose was $14.3 \mu \mathrm{g} / \mathrm{mL}, 18.2$ $\mu \mathrm{g} / \mathrm{mL}, 0.48 \mu \mathrm{g} / \mathrm{mL}$, respectively. The combination of different concentrations of glucose oxidase and glucose could significantly inhibit the growth of Agrobacterium and Escherichia coli in logarithmic phase. The filter paper containing supernatant of the fermentation medium, supernatant of the cell lysate, and precipitation of cell lysate had no inhibitory effect on Agrobacterium and E. coli. The minimum inhibitory concentration of hydrogen peroxide on the plate culture of Agrobacterium and E. coli was $5.6 \times 10^{3} \mu \mathrm{g} / \mathrm{mL}$ and $6.0 \times 10^{3} \mu \mathrm{g} / \mathrm{mL}$, respectively. 


\title{
Expression of Aspergillus niger glucose oxidase in Pichia pastoris and its antimicrobial activity against Agrobacterium and Escherichia coli
}

\author{
Yonggang Wang ${ }^{1,2^{*}}$, Jiangqin Wang ${ }^{1,2}$, Feifan Leng ${ }^{1,2}$, Jianzhong Ma $^{1,2 *}$, Alnoor Bagadi ${ }^{1}$ \\ 1 School of Life Science and Engineering, Lanzhou University of Technology, Lanzhou 730050, P. R. China \\ 2 Key Laboratory of Drug Screening and Deep Processing for Traditional Chinese and Tibetan Medicine of \\ Gansu Province, Lanzhou University of Technology, Lanzhou 730050, P. R. China \\ Corresponding author. School of Life Science and Engineering, Lanzhou University of Technology, \\ Langongping Road 287, Qilihe District, Lanzhou City, Gansu Province, PR China. E-mail address: \\ 412316788@163.com (YG Wang); mazj@lut.cn (JZ Ma)
}

Abstract The gene encoding glucose oxidase from Aspergillus niger ZM-8 was cloned and transferred to Pichia pastoris GS115, a transgenic strain P. pastoris GS115-His-GOD constructed. The growth curve of $P$. pastoris GS115-His-GOD was consistent with that of P. pastoris GS115-pPIC9K under non-induced culture conditions. Under methanol induction conditions, the growth of the GOD-transgenic strain was significantly lowered than P.pastoris GS115-pPIC9K with the induced-culture time increase, and the optical densities of GOD-transgenic strain reached one-third of that of the P.pastoris GS115-pPIC9K at 51h. The activity of glucose oxidase in the cell-free supernatant, the supernatant of cell lysate, and the precipitation of cell lysate was $14.3 \mathrm{U} / \mathrm{mL}, 18.2 \mathrm{U} / \mathrm{mL}$ and $0.48 \mathrm{U} / \mathrm{mL}$, respectively. The specific activity of glucose oxidase was 8.3 $\mathrm{U} / \mathrm{mg}, 6.52 \mathrm{U} / \mathrm{mg}$ and $0.73 \mathrm{U} / \mathrm{mg}$, respectively. The concentration of hydrogen peroxide formed by glucose oxidase from supernatant of the fermentation medium, the supernatant of the cell lysate, and the precipitation of cell lysate catalyzing $0.2 \mathrm{M}$ glucose was $14.3 \mu \mathrm{g} / \mathrm{mL}, 18.2 \mu \mathrm{g} / \mathrm{mL}, 0.48 \mu \mathrm{g} / \mathrm{mL}$, respectively. The combination of different concentrations of glucose oxidase and glucose could significantly inhibit the growth of Agrobacterium and Escherichia coli in logarithmic phase. The filter paper containing supernatant of the fermentation medium, supernatant of the cell lysate, and precipitation of cell lysate had no inhibitory effect on Agrobacterium and E. coli. The minimum inhibitory concentration of hydrogen peroxide on the plate culture of Agrobacterium and E. coli was $5.6 \times 10^{3} \mu \mathrm{g} / \mathrm{mL}$ and $6.0 \times 10^{3} \mu \mathrm{g} / \mathrm{mL}$, respectively.

Keywords: Aspergillus niger; Pichia pastoris; Glucose oxidase; Antimicrobial activity

\section{Introduction}

Since 1929, Fleming's discovery on bactericides prompted a search for antimicrobial substance in moulds of the same genus. Coulthard et al. (1942) first described an antibacterial glucose aerohydrogenes (Notatin, firstly named as penicillin A) from Penicillium notatum Westling. Almost at the same time, other substances 
including penicillin B and penatin also were isolated from Penicillium and exhibited good antimicrobial activity (Bruggen et al., 1943; Kocholaty, 1943; Roberts et al., 1943;). Until 1963, Muller found that penicillin $\mathrm{B}$ and penatin were identical to notatin, and all of them belong to Glucose oxidase (GOD) (Bentley, 1963), which played the important roles in the inhibition of microbial growth. Thereafter, Glucose oxidase, referred to as an an ideal enzyme, has attracted the attention of researchers (Bentley, 1963; Park et al., 2000; Crognale et al., 2006; Belyad, Karkhanei \& Raheb, 2018; Li et al., 2019; Tu et al., 2019).

Glucose oxidase ( $\beta$-D-glucose: oxygen 1-oxidoreductase, GOD, EC 1.1.3.4) catalyzes the oxidation of glucose to gluconic acid and hydrogen peroxide in the presence of molecular oxygen according to the following reactions (Hodgkins et al., 1993; Yamaguchi et al., 2007; Meng et al., 2014):

$$
\beta \text {-D-glucose }+\mathrm{O}_{2} \stackrel{\text { GOD }}{\longrightarrow} \beta \text {-D-glucono- } \delta \text {-lactone }+\mathrm{H}_{2} \mathrm{O}_{2}
$$

$$
\beta \text {-D-glucono- } \delta \text {-lactone }+\mathrm{H}_{2} \mathrm{O} \stackrel{\text { Spontaneously }}{\longrightarrow} \text { D-gluconic acid }
$$

GODs are produced by molds such as Aspergillus niger and Penicillium (Frederick et al., 1990; Meng et al., 2014; Qiu et al., 2016; Farshad, Amin \& Catherine, 2018). Many literatures reported that GOD could inhibit the growth of microbes in foods or food preparation media (Tiina \& Sandholm, 1989; Yoo \& Rand, 1995; Li et $a l ., 2019)$. And it has been proven that this type of antibacterial compound is hydrogen peroxide $\left(\mathrm{H}_{2} \mathrm{O}_{2}\right)$, which is active against $\mathrm{G}^{+}$and $\mathrm{G}^{-}$bacteria (Malherbe et al., 2003). This bacteriostatic effect of hydrogen peroxide is mainly attributed to the peroxidation of membrane lipids (Roberts et al., 1943; Piard \& Desmazeaud, 1991). In laboratory-scale testing, refrigerated shelf life of GOD-treated fish was improved by 67\% over untreated fish (Field et al., 1986). Moreover, GOD was able to inhibit growth of Pseudomonas spp. which are the main psychrotrophic spoilage microorganisms of chilled poultry (Barnes \& Impey, 1968; Cox et al., 1975). GODs are also used in many medical applications. Sandholm and his co-workers suggested that all mastitis pathogens were sensitive to the glucose oxidase-lactoperoxidase system (Sandholm et al., 1988). GOD was also used as an antimicrobial agent in oral care (Szynol et al., 2004). The effect of honey on clearing infections in a wide range of wounds, which often did not respond to conventional therapy, was result of the antibacterial activity of hydrogen peroxide that is produced by GOD in honey (Molan, 2001; Bang, Buntting \& Molan, 2003; Khadivi et al., 2017).

As above-mentioned descriptions, GODs are prepared mainly from the fermentation of Aspergillus (Tu et al., 2019), Penicillium (Bodade, Khobragade \& Arfeen, 2010; Khan et al., 2016), Bacillus sp. (Xu et al., 2018), Cladosporium neopsychrotolerans (Ge et al., 2020), transgenic Trichoderma reesei (Wu et al., 2017), transgenic P. pastoris (Park et al., 2000; Crognale et al., 2006; Yamaguchi et al., 2007; Rocha et al., 2010; Fang et al., 2015; Belyad, Karkhanei \& Raheb, 2018), and directly used in industry (Wong, Wong \& Chen, 2008) as a control agent against pathogenic microorganism (Hopkinsa et al., 2019; Lee et al., 2019; Li et al., 2019) or a key catalyst for bioelectrochemical applications (Visvanathan et al., 2018; Mano, 2019). However, Very little information is available whether a glucose oxidase-secreting microbe could inhibit growth of its surrounding living things and become an ecological bacteriostatic agent. As we all know, chemical control is 
still the main method used to control the incidence of grey mould, chemical disinfectant could leave unsafe residues on plant materials and can drive resistance in pathogens, as well as contribute to environmental pollution. In this study, we here reported a new biological control strategy (Dal et al., 2008) for controlling the growth of pathogenic microorganism. In detail, the gene coding for glucose oxidase from A. niger ZM-8 was expressed under the control of inducible alcohol oxidase 1 (AOX-1) promoter in yeast $P$. pastoris. The antimicrobial property of the glucose oxidase enzyme was evaluated..

\section{Materials and Methods}

\section{Strains and Plasmids}

A $1749.0 \mathrm{bp}$ GOD gene fragment was amplified from the genomic DNA of Aspergillus niger ZM-8 by the CTAB method (Porebski, Bailey \& Baum, 1997). Primers for PCR were designed as sTable 1 based on conserved sequences of glucose oxidase gene (NO. JO5242) from GenBank Database, and then cloned into plasmid pUC19, The linearized vector pUC19- His-GOD by Sma I was inserted into the S. cerevisiae $\alpha$-factor secretion signal molecule pPIC9k (Invitrogn) to generate the expression vector pPIC9k-His-GOD under the action of the promoter AOX-1..The identified recombinant plasmid pPIC9K-His-GOD was linearized by $B g l$ $\Pi$ and transformed into P. pastoris GS115 cells by electroporation. The electro-competent $P$. pastoris GS115 cells were prepared using standard methods (Manivasakam \& Schiestl, 1993). The electroporation was performed using a Gene Pulser (Bio-Rad, US) at $1.5 \mathrm{kV}, 40.0 \mu \mathrm{F}$, and $150.0 \Omega$ according to manufacturer's instruction.

\section{Screening of Clones and Determination of Biomass}

The recombinant yeast clones were screened on yeast extract peptone dextrose (YPD) $[1 \%(w / v)$ yeast extract, $2 \%(w / v)$ tryptone, $2 \%(w / v)$ dextrose, $2 \%(w / v)$ agar] plus $1 \mathrm{M}$ sorbitol (YPDS) plates containing $100.0 \mu \mathrm{g} / \mathrm{mL}$ G418 (Invitrogen) for 2.0 to 4.0 days. Potential high-level secretion transformants were obtained from the YPDS agar plates containing a higher G418 concentration $(300.0 \mu \mathrm{g} / \mathrm{mL})$. All these potential highlevel secretion clones were confirmed by PCR using genomic DNA as the templates.

One colony was picked among several high copy clones obtained from the plate containing $P$. pastoris GS115-pPIC9k-His-GOD. P. pastoris GS115-pPIC9k was used as a negative control for the experiment. Clones were inoculated in Buffered Glycerol-complex medium (BMGY) [1\% $(w / v)$ yeast extract, 2\% $(w / v)$ tryptone, $100 \mathrm{mM}$ Potassium Phosphate ( $\mathrm{pH} 6.0), 1.34 \%(w / v)$ YNB, $4 \times 10^{-5} \mathrm{D}$-Biotin, $1 \%(w / v)$ glycerol], and cultured at $30{ }^{\circ} \mathrm{C}$ until $\mathrm{OD}_{600}=0.60$. The culture was then transferred to Buffered methanol-complex medium (BMMY) and cultured at $30^{\circ} \mathrm{C}$. The absorbance of growing culture was measured every 3 hours.

\section{Expression of GOD in Transgenic $P$. pastoris GS115}

The P. Pastoris strains were cultivated in BMGY medium at $30{ }^{\circ} \mathrm{C}$ for $24 \mathrm{~h}$. Biomass was generated after initial growth phase with glycerol as a carbon source. Finally, to induce AOX-1 dependent protein expression, the methanol fed-batch phase was started with methanol feed rate of $0.5 \mathrm{~mL} / 12.0 \mathrm{~h}$. Cell-free supernatant, the supernatant of cell lysate, and the precipitate of cell lysate was collected, and crushed by ultrasonic. The 
103

104

105

106

107

108

109

110

111

112

113

114

115

116

117

118

119

120

121

122

123

124

125

126

127

128

129

130

131

132

133

134

135

136

137

ultrasonication conditions used was 15 s, 25 s, 380 w, 99 times, and then stored at $4{ }^{\circ} \mathrm{C}$ (Cereghino \& Cregg, 2000).

\section{Analysis of Glucose Oxidase Activity}

$P$. pastoris GS115-His-GOD-01 and P. pastoris GS115-pPIC9k were cultured at $30{ }^{\circ} \mathrm{C}$ with supplement of $0.5 \%$ methanol per $12 \mathrm{~h}$. Activities of glucose oxidase from cell-free supernatant, cell lysate supernatant and precipitation were carried out according to Gemba et al. (1971) with a slight modification. In detail, the reaction system consisting of $4.0 \mathrm{~mL}$ of reaction mixture $(0.20 \mathrm{M}$ Acetic acid-Sodium acetate, $\mathrm{pH} 5.2 ; 0.2 \mathrm{M}$ glucose and $1.0 \mathrm{mM}$ Indigo Carmine) and $2.0 \mathrm{~mL}$ of the appropriately diluted enzyme solution was added into and incubated for $10 \mathrm{~min}$ at $37^{\circ} \mathrm{C}$. Then, the reaction was stopped by boiling water bath for $13 \mathrm{~min}$. The absorbance was measured at a wavelength of $615.0 \mathrm{~nm}$. One unit (U) of Glucose oxidase activity was defined as the amuont of enzyme, that can oxidize $1.0 \mu \mathrm{M}$ of $\beta$-D-glucose to D-gluconic acid and $\mathrm{H}_{2} \mathrm{O}_{2}$ per 3 minute at $\mathrm{pH} 6.0$ and $30^{\circ} \mathrm{C}$. All reactions were performed in triplicate. The formula of enzyme activity as follows:

$$
X_{0}=\left[\left(A-A_{0}\right) \times K+C_{0}\right] \times V \times F
$$

$\mathrm{X}_{0}$ : Enzyme activity; $\mathrm{A}$ : Absorbance value of trichloroacetic acid instead of glucose as the control; $\mathrm{A}_{0}$ : Absorbance value of the sample solution; K: Slope of the standard curve; $\mathrm{C}_{0}$ : Intercept of the standard curve. V: the volume of sample solution; F: the dilution factor.

\section{The specific activity of GOD}

Protein concentrations of cell-free liquid, cell lysate supernatant and precipitation from P. pastoris GS115His-GOD-01 and P. pastoris GS115-pPIC9K were determined by the method of Bradford (Hammond \& Kruger, 1988). Absorbance was measured at $615 \mathrm{~nm}$ wavelength and specific activity of GOD was the value of activity divided by the value of protein concentrations.

Antibacterial effects of Glucose and Glucose Oxidase System on Growth of Agrobacterium and E. coli in

\section{Liquid Medium}

Glucose oxidase and glucose were used in three dilution-set combinations. The concentration of glucose used were 1.0, 2.5 and $5.0 \mathrm{mg} / \mathrm{mL}$ respectively. The GOD was from fermentation supernatant of transgenic $P$. pastoris GS115-His-GOD-01 that was induced by methanol and fermentation supernatant from P. pastoris GS115-pPIC9K as control. Concentrations of GOD used was 1.0, 5.0 and 10.0 U/mL. The GOD and glucose solutions were added in the medium of YEP or LB and arranged in a Latin-square design to study the effects of substrates and enzyme on growth of Agrobacterium LBA4404 and E. coli DH5 $\alpha$ by measuring optical density in $600 \mathrm{~nm}$.

\section{GOD Antibacterial Activity to Agrobacterium and E. coli on Agar Plates}

The antibacterial activity of GOD produced by P. pastoris GS115-His-GOD-01 against A. tumefaciens LBA4404 and E. coli DH5 $\alpha$ (stored in Dr. Ma Jianzhong's laboratory of Lanzhou University of Technology) was determined. Cultivate to bacterial liquid $\mathrm{OD}_{600}=1.0$, spread on YPE (1\% (w/v) yeast extract, $1 \%(\mathrm{w} / \mathrm{v})$ tryptone, $0.5 \%(\mathrm{w} / \mathrm{v}) \mathrm{NaCl}$ and $1.5 \%(\mathrm{w} / \mathrm{v})$ Agar) plates or LB (1\% (w/v) yeast extract, $2 \%(\mathrm{w} / \mathrm{v})$ tryptone, $2 \%$ 
(w/v) $\mathrm{NaCl}$ and $1.5 \%(\mathrm{w} / \mathrm{v})$ agar) plates, on 51 hours after adding methanol, add cell-free liquid, sonicate the supernatant by precipitating, collect the pellet and resuspend the pellet in an ice bath, immerse it in sterile filter paper, and inoculate with $0.20 \mathrm{M}$ A. tumefaciens LBA4404 or E. coli DH5 $\alpha$ on the surface of the glucose plate, observe its antibacterial effect.

\section{Antibacterial Activity of Hydrogen Peroxide Solution to Agrobacterium and E. coli on Agar Plates}

The inhibitory effects of $A$. tumefaciens LBA4404 and E. coli DH5 $\alpha$ and the minimum hydrogen peroxide concentration to inhibit bacterial growth were detected. A. tumefaciens LBA4404 was cultured with shaking at $28{ }^{\circ} \mathrm{C}$ to $\mathrm{OD}_{600}=1.0$, and $200 \mu \mathrm{L}$ was coated on YPE medium, and then put into filter paper with different concentrations of hydrogen peroxide solution, and cultured at $28{ }^{\circ} \mathrm{C}$ for 14 hours, and observed antibacterial effect. E. coli DH5 $\alpha$ was shake-cultured at $37{ }^{\circ} \mathrm{C}$ to $\mathrm{OD}_{600}=1.5,200 \mu \mathrm{L}$ was applied to LB medium, and then filter paper of different concentrations of hydrogen peroxide solution was placed. The culture was allowed to stand at $37^{\circ} \mathrm{C}$ for 14 hours to observe the inhibitory effect.

\section{Results}

\section{Vector construction and Screening of transgenic $P$. pastoris Clones}

P. pastoris strain GS115 was transformed using linearized pPIC9K-His-GOD as described in materials and methods to yield P. pastoris GS115-His-GOD (sFig. 1). Twelve clones were obtained and confirmed by PCRtesting for gene integration. These clones were then screened on YPDS plates with different concentrations of Geneticin (G418), i.e. $100 \mathrm{mM}, 200 \mathrm{mM}$, and $300 \mathrm{mM}$, respectively. A positive transgenic clone, designated as P. pastoris GS115-His-GOD 01 was grown on the YPDS plate with a high Geneticin concentration and was considered for subsequent experiments.

\section{Expression of the GOD Affecting the Growth of the GOD-transgenic Strain}

Hydrogen peroxide, one of the products by GOD, injures living cells. In line with this statement, growth of the GOD-transgenic strain, P. pastoris GS115-His-GOD 01 was analyzed. Compared to P. pastoris GS115pPIC9K, the growth of $P$. pastoris GS115-His-GOD 01 was slightly decreased during 51 st hour of incubation under GOD uninduced condition (Fig. 1A). Its optical density at $600 \mathrm{~nm}$ was 0.95 -fold of that of $P$. pastoris GS115-pPIC9K at the time point of $51.0 \mathrm{~h}$. However, the growth of P. pastoris GS115-His-GOD 01 was significantly lowered if the GOD was induced by methanol (Fig. 1B). During the growth of $51.0 \mathrm{~h}$, the optical densities of $P$. pastoris GS115-His-GOD 01 were 0.54 -fold of that of P. pastoris GS115-pPIC9K at 18.0h, 0.43 -fold at $36 \mathrm{~h}$, and 0.37 -fold at $51.0 \mathrm{~h}$, respectively. The inhibited growth of the GOD-transgenic $P$. pastoris could be attributed to the expression of the foreign GOD and, hereafter, accumulation of $\mathrm{H}_{2} \mathrm{O}_{2}$.

\section{Activities of the Glucose Oxidase}

After 51 hour-induced incubation, the cultures were processed into three parts of which were the cell-free supernatant, the supernatant and the precipitation of the cell lysates. The activities of the GOD preparations from P. pastoris GS115-His-GOD 01 were $14.27 \mathrm{U} / \mathrm{mL}$ in the cell-free supernatant, $18.2 \mathrm{U} / \mathrm{mL}$ in the supernatant of the cell lysate, and $0.48 \mathrm{U} / \mathrm{mL}$ in the precipitation (Fig. 2A). As a control, the activities of the three GOD preparations from P. pastoris GS115-pPIC9K were $3.22 \mathrm{U} / \mathrm{mL}, 1.76 \mathrm{U} / \mathrm{mL}$ and $0.41 \mathrm{U} / \mathrm{mL}$, 
respectively (Fig. 2A). The specific activities of the three GOD preparations from P. pastoris GS115-His-GOD 01 were $8.30 \mathrm{U} / \mathrm{mg}$ in the cell-free supernatant, $6.52 \mathrm{U} / \mathrm{mg}$ in the supernatant of the cell lysate, and $0.73 \mathrm{U} / \mathrm{mg}$ in the precipitation, respectively (Fig. 2B). The specific activities of the three preparations from P. pastoris GS115-pPIC9K were $0.859 \mathrm{U} / \mathrm{mg}, 1.483 \mathrm{U} / \mathrm{mg}$, and $0.529 \mathrm{U} / \mathrm{mg}$, respectively (Fig. 2B). According to the specific activities, the cell-free supernatant of P. pastoris GS115-His-GOD 01 had the highest value, but the supernatant of the cell lysate of $P$. pastoris GS115-pPIC9K gave the highest specific activity. These results suggested that the native GOD of $P$. pastoris GS115 was mainly an intracellular enzyme. In the GODtransgenic P. pastoris GS115, the enzyme was mainly secreted. This is in accordance with that the recombinant GOD was directed to an extra-cellular fraction by a signal peptide, $\alpha$-mating factor.

\section{The concentration of Hydrogen Peroxide from GOD Catalyzed Glucose}

The concentration of hydrogen peroxide produced by GOD from $P$. pastoris GS115-His-GOD-01 and $P$. pastoris GS115-pPIC9K catalytic glucose was showed in Fig. 3. According to the results in Fig. 3, the concentration of hydrogen peroxide was $14.3 \mu \mathrm{g} / \mathrm{mL}$ and $3.05 \mu \mathrm{g} / \mathrm{mL}$ in cell-free supernatant. The concentration of $\mathrm{H}_{2} \mathrm{O}_{2}$ from the supernatant of cell lysate was $18.2 \mu \mathrm{g} / \mathrm{mL}$ and $1.86 \mu \mathrm{g} / \mathrm{mL}$, however, that of the precipitate of cell lysate was $0.48 \mu \mathrm{g} / \mathrm{mL}$ and $0.46 \mu \mathrm{g} / \mathrm{mL}$. These results indicated that the GOD could be secreted out of the cells with the form of soluble protein.

Inhibition of the GOD preparations on the Growth of $A$. tumefaciens LBA4404 and $E$. coli in Liquid

\section{Medium}

The GOD was prepared in fermentation supernatant of $P$. pastoris GS115-His-GOD 01. When the concentration of GOD was set as $1.0 \mathrm{U} / \mathrm{mL}$, the growth curve of $A$. tumefaciens LBA4404 and E. coli DH5 $\alpha$ under the gradually increasing of Glu were shown in Fig. 4 (A, B). From these two figures, almost no inhibition to the growth of A. tumefaciens LBA4404 compared with the control that was added with equal volume of $P$. pastoris GS115-pPIC9K fermentation supernatant. However, the marked inhibition to the growth of $E$. coli $\mathrm{DH} 5 \alpha$ were observed from $4^{\text {th }}$ hours to $14^{\text {th }}$ hours with substrate concentration increasing (Fig. 4B). When the concentration of GOD was set as $5.0 \mathrm{U} / \mathrm{mL}$, a slight inhibition on the growth of A. tumefaciens LBA4404 after $14^{\text {th }}$ hours with substrate concentration increasing (Fig. 4C), and the same change trends with Fig. 4B can be observed for the inhibition on E. coli DH5a from Fig. 4D. With the increasing of Glu concentration, the delay of growth of A. tumefaciens LBA4404 also be observed by the given GOD concentration of $10 \mathrm{U} / \mathrm{mL}$ (Fig. 4E), and the minor effect on E. coli DH5 $\alpha$ also could be found in Fig. 4F. Conclusions were drawn from Fig. 4, it showed these combinations did not completely inhibit growth of $A$. tumefaciens and LBA4404 E. coli DH5a, but influenced the time at which growth was initiated. Delay of growth initiation was greatest with the enzyme concentration, $5.0 \mathrm{U} / \mathrm{mL}$, and the impact increased also with substrate concentration.

Antibacterial effects of Glucose and Glucose Oxidase on Growth of A. tumefaciens and E.coli on Agar Plates 
Analysis of the antibacterial activity of hydrogen peroxide $\left(\mathrm{H}_{2} \mathrm{O}_{2}\right)$ produced by GOD catalyzed substrates glucose. A. tumefaciens LBA4404 (Fig. 5A) and E.coli DH5a (Fig. 5B) were plated on YPE or LB which were contained 0.2 M glucose. Filter papers were soaked by cell-free supernatant, the supernatant of cell lysate, and the precipitate of cell lysate from $P$. pastoris GS115-His-GOD 01, cell-free supernatant of $P$. pastoris GS115pPIC9K as the negative control. The results showed that $\mathrm{H}_{2} \mathrm{O}_{2}$ derived from glucose which catalyzed by GOD had no effect on the growth of $A$. tumefaciens LBA4404 and E. coli DH5 $\alpha$.

\section{Antibacterial Activity of Hydrogen Peroxide Solution to A. tumefaciens LBA4404 and E.coli DH5a}

To detect the minimum concentration of hydrogen peroxide solution inhibit the growth of A. tumefaciens LBA4404 and E.coli DH5 $\alpha$, the sterile filter papers were soaked with a volume of $10 \mu \mathrm{L}$ hydrogen peroxide that was diluted to different concentrations. Different concentrations of hydrogen peroxide solution effect on $A$. tumefaciens LBA4404 and E.coli DH5 $\alpha$ were determined. As shown in Fig. 6 (A, B), the inhibition effect of $\mathrm{H}_{2} \mathrm{O}_{2}$ on the two strains gradually decreased with the concentration reducing. The diameters of inhibition zone for these strains also were displayed in Fig. $6(\mathrm{C}, \mathrm{D})$, implying that the minimum concentration of hydrogen peroxide solution inhibits the growth of A. tumefaciens LBA4404 and E.coli DH5 $\alpha$ was $5.6 \times 10^{3}$ $\mu \mathrm{g} / \mathrm{mL}$ and $6.0 \times 10^{3} \mu \mathrm{g} / \mathrm{mL}$.

\section{Discussion}

As evident from the abovementioned reviews, Glucose oxidase acts as a bacteriostatic agent by catalyzing hydrogen peroxide production via glucose oxidation (Wong, Wong \& Chen, 2008; Bankar et al., 2009). At present, large-scale production of the enzyme was completed by good stability strains and fermentation technology (Ge et al., 2020). Although, many strains (Bodade, Khobragade \& Arfeen, 2010; Khan et al., 2016; $W u$ et al., 2017) have been screened for producing this enzyme efficiently, only a few strains could be applied to commercial production. Therefore, more strategies need to be developed by constructing different bioreactor, modified enzyme, or enzyme engineering technology. Compared with a mass of glucose oxidase as an antibacterial agent applied in food preservation (Lee et al., 2019; Li et al., 2019), uses the GOD-transgenic strains or their fermented supernatants directly are easy, inexpensive, and widely available (Dal et al., 2008). However, little information is available whether a glucose oxidase-secreting microbe could inhibit the growth of its surrounding living things. As Dal et al. (2008) description, yeast could inhibit the grey mould growth, the novel viewpoint could be used to the development of bacteriostatic agent by genetic manipulations. Studies have found that most $P$. pastoris expression systems use methanol-induced ethanol oxidase promoters to express GOD (Crognale et al., 2006; Yamaguchi et al., 2007; Belyad, Karkhanei \& Raheb, 2018), and the concentration of methanol directly affects cell growth and protein expression (Cereghino et al., 2002; Xiao, Wang \& Chen, 2004; Daly \& Hearn, 2005). Crognale et al. (2006) described a genetically modified P. pastoris X 33 with the gene encoding the GOX from P. variabile P16, and the activity only reached at $50 \mathrm{U} / \mathrm{mL}$. Kovačević et al. (2014) cloned several mutated glucose oxidase genes from A. niger M12 and expressed them in P. pastoris KM71H. The highest activity of the GOD came up to $17.5 \mathrm{U} / \mathrm{mL}$ of fermentation media. Gu et al. (2015) reported recently that a yield of GOD reached $21.81 \mathrm{~g} / \mathrm{L}$, with an activity of $1972.9 \mathrm{U} / \mathrm{mL}$, in $P$. 
245

246

247

248

249

250

251

252

253

254

255

256

257

258

259

260

261

262

263

264

pastoris $\mathrm{S} 17$ of which is a genetically modified strain by manipulating genes involved in protein folding machinery and abnormal folding stress responses. Belyad, Karkhanei \& Raheb (2018) also cloned the GOD gene from A. niger ATCC 9029 and inserted into the pPIC9 vector for protein expression in P. pastoris GS115 by the alcohol oxidase promoter, but no the expression ability and enzyme activity were introduced. Although the above literatures has been reported the produce of GOD, there are no detailed determination on the activity of glucose oxidase in supernatant of the fermentation medium, the supernatant of the cell lysate, and the precipitation of cell lysate. In particular, there is no evidence of hydrogen peroxide production and bacteriostatic properties analysis. In this paper, the GOD-encoding gene from A. niger ZM-8 was cloned and transferred into $P$. pastoris GS115 to yield a transgenic strain, which can excrete GOD to medium by the way of methanol induction. The activity of glucose oxidase in supernatant of the fermentation medium, the supernatant of the cell lysate, and the precipitation of cell lysate was $14.3 \mathrm{U} / \mathrm{mL}, 18.2 \mathrm{U} / \mathrm{mL}$ and $0.48 \mathrm{U} / \mathrm{mL}$, respectively. Corresponding these determined samples, The concentration of hydrogen peroxide formed by glucose oxidase can reached at $14.3 \mu \mathrm{g} / \mathrm{ml}, 18.2 \mu \mathrm{g} / \mathrm{ml}, 0.48 \mu \mathrm{g} / \mathrm{ml}$, respectively. According to our results, the GOD-transgenic $P$. pastoris has to produce more enzyme molecules or higher active enzymes in order to inhibit microbes. Although the growth of $P$. pastoris GS115-His-GOD was found to be seriously inhibited during the period of methanol induction, its fermented supernatants containing the GOD activity can really reduce the growth of E. coli and A. tumefaciens in liquid culture (Fig. 4). In contrast, the GOD-soaked filter papers didn't exhibit any inhibition to the growth of A. tumefaciens and E. coli on the solid medium (Fig. 5). At present, it was not sure that it resulted from no enough oxygen or no enough GOD. As shown in Fig. 6, hydrogen peroxide can inhibit growth of $A$. tumefaciens and E. coli on solid medium, and the concentrations at least are $5.6 \times 10^{3} \mu \mathrm{g} / \mathrm{mL}$ and $6.0 \times 10^{3} \mu \mathrm{g} / \mathrm{mL}$, respectively. To reach the concentration of hydrogen peroxide, the activity of the GOD produced from the transgenic strain should be at least increased 300-fold. To achieve antibacterial applications by GOD-transgenic P. pastoris directly, there will be more studies to be done in enzyme activity improvement and oxygen-offering system. These results could provide a new insight on bacteriostatic agent.

\section{Conclusion}

This study cloned a gene encoding Aspergillus niger ZM-8 glucose oxidase and transferred it to $P$. pastoris to form a transgenic strain GS115-His-GOD. Compared with GS115-pPIC9K, the transgenic P. pastoris GS115-His-GOD could express glucose oxidase by methanol induction, The hydrogen peroxide could be produced with Glucose as the substrate during the fermentation process, and exhibited the inhibition activities on the growth of A. tumefaciens and E. coli.

\section{Compliance with ethical standards}

\section{Conflict of Interest}


No conflict of interest declared.

Acknowledgment

This study was financially supported by Chinese National Natural Science Foundation (No. 31760028, 31460032), and the Fundamental Research Funds for Key Laboratory of Drug Screening and Deep Processing for Traditional Chinese and Tibetan Medicine of Gansu Province (No. KZZY20180605), and the Youth Talent Support Program of Lanzhou University of Technology (No. 2018).

\begin{abstract}
References
Bang LM, Buntting C, Molan P. 2003. The effect of dilution on the rate of hydrogen peroxide production in honey and its implications for wound healing. Journal of Alternative and Complementary Medicine 9(2):267-273 DOI 10.1089/10755530360623383.
\end{abstract}

Bankar SB, Bule MV, Singhal RS, Ananthanarayan L. 2009. Glucose oxidase-an overview. Biotechnology Advances 27(4):489-501 DOI 10.1016/j.biotechadv.2009.04.003.

Barnes EM, Impey CS. 1968. Psychrophilic spoilage bacteria of poultry. Journal of Applied Bacteriology 31(1):97-107 DOI 10.1111/j.1365-2672.1968.tb00345.x.

Belyad F, Karkhanei AA, Raheb J. 2018. Expression, characterization and one step purification of heterologous glucose oxidase gene from Aspergillus niger ATCC 9029 in Pichia pastoris. EuPA open proteomics 19:1-5 DOI 10.1016/j.euprot.2018.09.001.

Bentley R. 1963. "Glucose Oxidase" in The Enzymes vol. 7, P. D. Boyer et al., Eds. (Academic Press, New York):567-586.

Bodade RG, Khobragade CN, Arfeen S. 2010. Optimization of culture conditions for glucose oxidase production by a Penicillium chrysogenum SRT 19 strain. Engineering in Life Science 10(1):35-39 DOI 10.1002/elsc.200900030.

Bruggen JTV, Reithel FJ, Cain CK, Katzman PA, Doisy EA, Muir RD, Roberta EC, Gaby WL, Homan DM, Jones LR. 1943. Penicillin B: purification and mode of action. Journal of Biological Chemistry 148(2):365-378 DOI 10.1086/394673.

Cereghino GPL, Cereghino JL, Ilgen C, Cregg JM. 2002. Production of recombinant proteins in fermenter cultures of the yeast Pichia pastoris. Current opinion in biotechnology 13(4):329-332 DOI 10.1016/s09581669(02)00330-0.

Cereghino JL, Cregg JM. 2000. Heterologous protein expression in the methylotrophic yeast Pichia pastoris. FEMS Microbiology Reviews 24(1):45-66 DOI 10.1016/s0168-6445(99)00029-7. 
Coulthard CE, Short WF, Michaelis R, Sykes G, Skrimshire GEH, Standfast A FB, Birkinshaw JH, Raistrick H. 1942. Notatin: an antibacterial glucose aerohydrogenes from Penicillium notatum Westling. Nature 150:634-635 DOI 10.1038/150634a0.

Cox NA, Juven BJ, Thomson JE, Mercuri AJ, Chew V. 1975. Spoilage odors in poultry meat produced by pigmented and nonpigmented Pseudomonas. Poultry Science 54(6):2001-2006 DOI 10.3382/ps.0542001.

Crognale S, Pulci V, Brozzoli V, Petruccioli M, Federici F. 2006. Expression of Penicillium variabile P16 glucose oxidase gene in Pichia pastoris and characterization of the recombinant enzyme. Enzyme and Microbial Technology 39(6):1230-1235 DOI 10.1016/j.enzmictec.2006.03.005.

Dal BG, Monaco C, Rollan MC, Lampugnani G, Arteta N, Abramoff C, Ronco L, Stocco M. 2008. Biocontrol of postharvest grey mould on tomato by yeasts. Journal of Phytopathology 156(5):257-263 DOI 10.1111/j.1439-0434.2007.01351.x.

Daly R, Hearn MT. 2005. Expression of heterologous proteins in Pichia pastoris: a useful experimental tool in protein engineering and production. Journal of Molecular Recognition 18(2):119-138 DOI 10.1109/4.953490.

Fang J, You R, Song C, Guo RF. 2015. Production of glucose oxidase and its application in feed industry. Feed Review 10:1-7 DOI 10.3969/j.issn.1001-0084.2015.10.001.

Farshad D, Amin Z, Catherine M. 2018. In silico and in vivo analysis of signal peptides effect on recombinant glucose oxidase production in nonconventional yeast yarrowia lipolytica. World Journal of Microbiology and Biotechnology 34(9):128 DOI 10.1007/s11274-018-2512-x.

Field CE, Pivarnik LF, Barnett SM, Jr AGR. 1986. Utilization of glucose oxidase for extending the shelflife of fish. Journal of Food Science 51(1):66-70 DOI 10.1111/j.1365-2621.1986.tb10837.x.

Frederick KR, Tung JT, Emerick RS, Masiarz FR, Schopter LM. 1990. Glucose oxidase from Aspergillus niger: cloning, gene sequence, secretion from saccharomyces cerevisiae and kinetic analysis of a yeastderived enzyme. Journal of Biological Chemistry 265(7):3793-3802 DOI 10.1021/bi00461a029.

Ge JZ, Jiang X, Liu WN, Wang Y, Huang HQ, Bai YG, Su XY, Yao B, Luo HY. 2020. Characterization, stability improvement, and bread baking applications of a novel cold-adapted glucose oxidase from Cladosporium neopsychrotolerans SL16. Food Chemistry 310:1-8 DOI 10.1016/j.foodchem.2019.125970.

Gu L, Zhang J, Du G, Chen J. 2015. Multivariate modular engineering of the protein secretory pathway for production of heterologous glucose oxidase in Pichia pastoris. Enzyme and Microbial Technology 68:33-42 DOI 10.1016/j.enzmictec.2014.10.006.

Hammond JBW, Kruger NJ. 1988. The Bradford method for protein quantization. Methods in Molecular Biology 32:9-15 DOI 10.1385/0-89603-268-X:9.

Hodgkins M, Mead D, Ballance DJ, Goodey A, Sudbery P. 1993. Expression of the glucose oxidase gene from Aspergillus niger in Hansenula polymorpha and its use as reporter gene to isolate regulatory mutants. Yeast 9(6):625-635 DOI 10.1002/yea.320090609. 
Hopkinsa EJ, Huclb P, Scanlonc MG, Nickersona MT. 2019. Effects of glucose oxidase and organic acids on the properties of a model low sodium dough prepared from Harvest and Pembina CWRS wheat. Journal of Cereal Science 89:1-8 DOI 10.1016/j.jcs.2019.102802.

Khadivi DF, Darvishi F, Dezfulian M, Madzak C. 2017. Expression and Characterization of Glucose Oxidase from Aspergillus niger in Yarrowia lipolytica. Molecular Biotechnology 59(8):307-314 DOI 10.1007/s12033-017-0017-8.

Khan I, Qayyum S, Ahmed S, Niaz Z, Fatima N, Chi ZM. 2016. Molecular cloning and sequence analysis of a pvgox gene encoding glucose oxidase in Penicillium viticola F1 strain and it's expression quantitation. Gene 592(2):291-302 DOI 10.1016/j.gene.2016.07.032.

Kocholaty W. 1943. Purification and properties of penatin: the second antibacterial substance produced by Penicillium notatum Westling. Science 2:73-86 DOI 10.1126/science.97.2512.186.

Kovačević G, Blažić M, Draganić B, Ostafe R, Jankulović MG, Fischer R. 2014. Cloning, heterologous expression, purification and characterization of M12 mutant of Aspergillus niger glucose oxidase in yeast Pichia pastoris KM71H. Molecular Biotechnology 56(4):305-311 DOI 10.1007/s12033-013-9709-x.

Lee I, Cheon HJ, Adhikari MD, Tran TD, Yeon KM, Kim MI, Kim J. 2019. Glucose oxidase-copper hybrid nanoflowers embedded with magnetic nanoparticles as an effective antibacterial agent. International Journal of Biological Macromolecules DOI 10.1016/j.ijbiomac.2019.11.129.

Li XJ, Xie XF, Xing FG, Xu L, Zhang J, Wang ZD. 2019. Glucose oxidase as a control agent against the fungal pathogen Botrytis cinerea in postharvest strawberry. Food Control 105:277-284 DOI 10.1016/j.foodcont.2019.05.037.

Malherbe DF, Toit MD, Otero RRC, Rensburg PV, Pretorius IS. 2003. Expression of the Aspergillus niger glucose oxidase gene in Saccharomyces cerevisiae and its potential applications in wine production. Applied Microbiology \& Biotechnology 61(5-6):502-511 DOI 10.1007/s00253-002-1208-0.

Manivasakam P, Schiestl RH. 1993. High efficiency transformation of Saccharomyces cerevisiae by electroporation. Nucleic Acids Research 21(18):4414-4415 DOI 10.1093/nar/21.18.4414.

Mano N. 2019. Engineering glucose oxidase for bioelectrochemical applications. Bioelectrochemistry 128:218-240 DOI 10.1016/j.bioelechem.2019.04.015.

Meng Y, Zhao M, Yang M, Zhang Q, Meng Y. 2014. Production and characterization of recombinant glucose oxidase from Aspergillus niger expressed in Pichia pastoris.Letters in Applied Microbiology 58(4):393-400 DOI 10.1111/lam.12202.

Molan PC. 2001. Potential of honey in the treatment of wounds and burns. American Journal of Clinical Dermatology 2(1):13-19 DOI 10.2165/00128071-200102010-00003.

Park EH, Shin YM, Lim YY, Kwon TH, Kim DH, Yang MS. 2000. Expression of glucose oxidase by using recombinant yeast. Journal of Biotechnology 81(1):35-44 DOI 10.1016/s0168-1656(00)00266-2.

Piard JC, Desmazeaud MJ. 1991. Inhibiting factors produced by lactic acid bacteria. 1. oxygen metabolites and catabolism end-products. Dairy Science and Technology 71(5):525-541 DOI 10.1051/lait:1991541. 
Porebski S, Bailey LG, Baum BR. 1997. Modification of a CTAB DNA extraction protocol for plants containing high polysaccharide and polyphenol components. Plant Molecular Biology Reporter 15(1):8-15 DOI $10.1007 / \mathrm{bf02772108.}$

Qiu ZJ, Guo YF, Bao XM, Hao JR, Sun GY, Peng BY, Bi WX. 2016. Expression of Aspergillus niger glucose oxidase in yeast Pichia pastoris SMD1168. Biotechnology \& Biotechnological Equipment 30(5):998-1005 DOI 10.1080/13102818.2016.1193442.

Roberts EC, Cain CK, Muir RD, Reithel FJ, Doisy EA. 1943. Penicillin b, an antibacterial substance from Penicillium notatum. Journal of Biological Chemistry 147(1):47-58 DOI 10.1515/bchm2.1943.277.4-6.284.

Rocha SN, José AN, María EC, María IGS, Gombert AK. 2010. Heterologous expression of glucose oxidase in the yeast Kluyveromyces marxianus. Microbial Cell Factories 9(1):4 DOI 10.1186/1475-2859-94.

Sandholm M, Ali-Vehmas T, Kaartinen L, Junnila M. 1988. Glucose oxidase (GOD) as a source of hydrogen peroxide for the lactoperoxidase (LPO) system in milk: antibacterial effect of the GOD-LPO system against mastitis pathogens. Zentralblatt Für Veterinärmedizin.reihe B.journal of Veterinary Medicine 35(1-10):346-352 DOI 10.1111/j.1439-0450.1988.tb00506.x.

Szynol A, de Soet JJ, Sieben-Van TE, Bos JW, Frenken LG. 2004. Bactericidal effects of a fusion protein of llama heavy-chain antibodies coupled to glucose oxidase on oral bacteria. Antimicrobial Agents and Chemotherapy 48(9):3390 DOI 10.1128/AAC.48.9.3390-3395.2004.

Tiina M, Sandholm M. 1989. Antibacterial effect of the glucose oxidase-glucose system on food-poisoning organisms. International Journal of Food Microbiology 8(2):165-74 DOI 10.1016/0168-1605(89)90071-8.

Tu T, Wang Y, Huang H, Wang Y, Jiang X, Wang Z, Yao B, Luo H. 2019. Improving the thermostability and catalytic efficiency of glucose oxidase from Aspergillus niger by molecular evolution. Food chemistry 281:163-170 DOI 10.1016/j.foodchem.2018.12.099.

Visvanathan R, Jayathilake C, Liyanage R, Sivakanesan R. 2018. Applicability and reliability of the glucose oxidase method in assessing $\alpha$-amylase activity. Food Chemistry 1-28 DOI 10.1016/j.foodchem.2018.09.114.

Wong CM, Wong KH, Chen XD. 2008. Glucose oxidase: natural occurrence, function, properties and industrial applications. Applied Microbiology and Biotechnology 78(6):927-938 DOI 10.1007/s00253-008$1407-4$.

Wu Y, Sun X, Xue X, Luo H, Su X. 2017. Overexpressing key component genes of the secretion pathway for enhanced secretion of an Aspergillus niger glucose oxidase in Trichoderma reesei. Enzyme and Microbial Technology 106:83-87 DOI 10.1016/j.enzmictec.2017.07.007.

Xiao SK, Wang L, Chen YQ. 2004. The study on improving expression levels of heterologous gene in Pichia pastoris. Biotechnology Bulletin 30(2):23-26 DOI 10.3969/j.issn.1002-5464.2004.02.006. 
417 Xu D, Sun L, Li C, Wang Y, Ye R. 2018. Inhibitory effect of glucose oxidase from, Bacillus, sp. 418 CAMT22370 on the quality deterioration of pacific white shrimp during cold storage. LWT 92:339-346 DOI $419 \quad 10.1016 /$ j.lwt.2018.02.025.

420 Yamaguchi M, Tahara Y, Nakano A, Taniyama T. 2007. Secretory and continuous expression of 421 Aspergillus niger glucose oxidase gene in Pichia pastoris. Protein Expression and Purification 55(2):273$422 \quad 278$ DOI 10.1016/j.pep.2007.05.006.

423 Yoo W, Rand AG. 1995. Antibacterial effect of glucose oxidase on growth of Pseudomonas fragi, as related 424 to pH. Journal of Food Science 60(4):868-871 DOI 10.1111/j.1365-2621.1995.tb06249.x. 
Figure 1

Fig. 1 Effects of GOD induction on the growth of the P. pastoris GS115-His-GOD 01

Fig. 1Effects ofGOD induction on the growth of the P. pastoris GS115-His-GOD 01. A:P. pastorisGS115-His-GOD 01 (Filled diamonds) andP. pastoris GS115-pPIC9K (Hollow squares) were incubated in YPD without methanol for $51 \mathrm{~h}$ at $30{ }^{\circ} \mathrm{C}$; B:P. pastoris GS115-His-GOD 01 (Filled diamonds) and $P$. pastoris GS115-pPIC9K (Hollow squares) were incubated in YPD with $0.5 \%$ methanol added every $12 \mathrm{~h}$ for $51 \mathrm{~h}$ at $30^{\circ} \mathrm{C}$. 
A

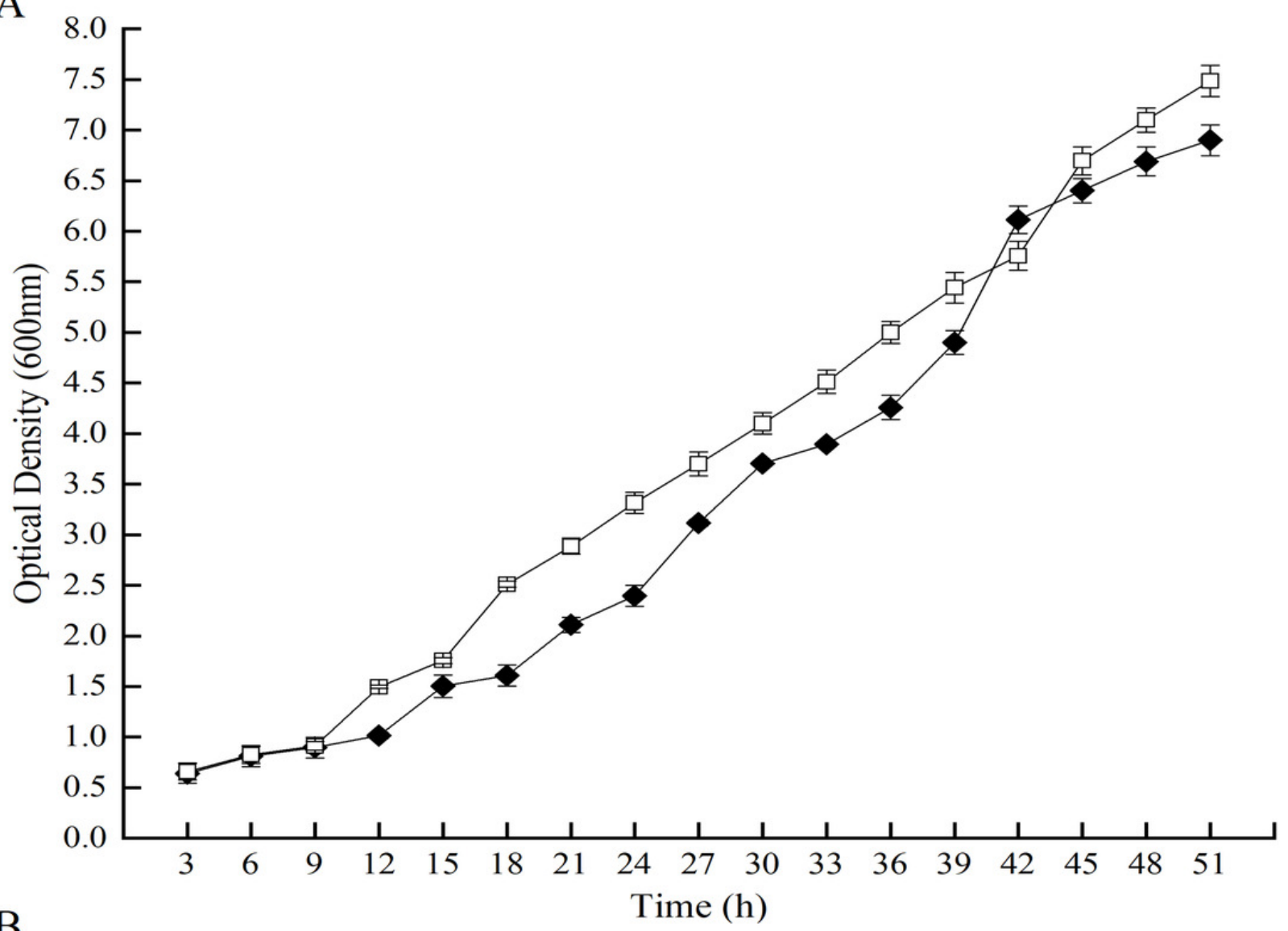

B

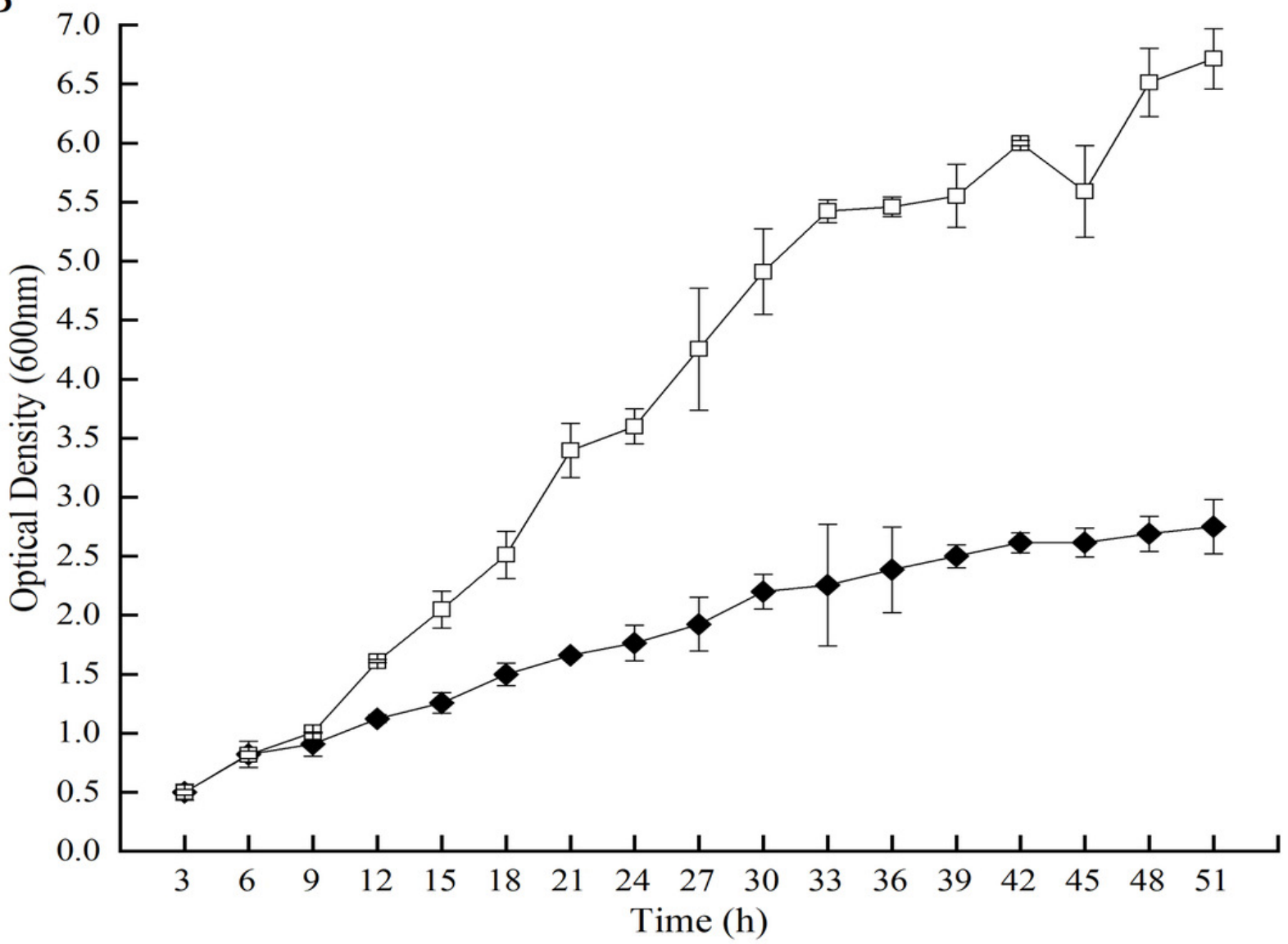




\section{Figure 2}

Fig. 2 Activities and specific activities of the GOD in the different preparations.

Fig. 2 Activities and specific activities of the GOD in the different preparations. A: The activities of the glucose oxidase in the cell-free supernatant, the supernatant of cell lysate, and the precipitate of cell lysate. B: The specific activities of the glucose oxidase in the cellfree supernatant, the supernatant of cell lysate, and the precipitate of cell lysate. Data from P. pastoris GS115-pPIC9K are exhibited in black columns and P. pastoris GS115-His-GOD 01 in colorless columns. 

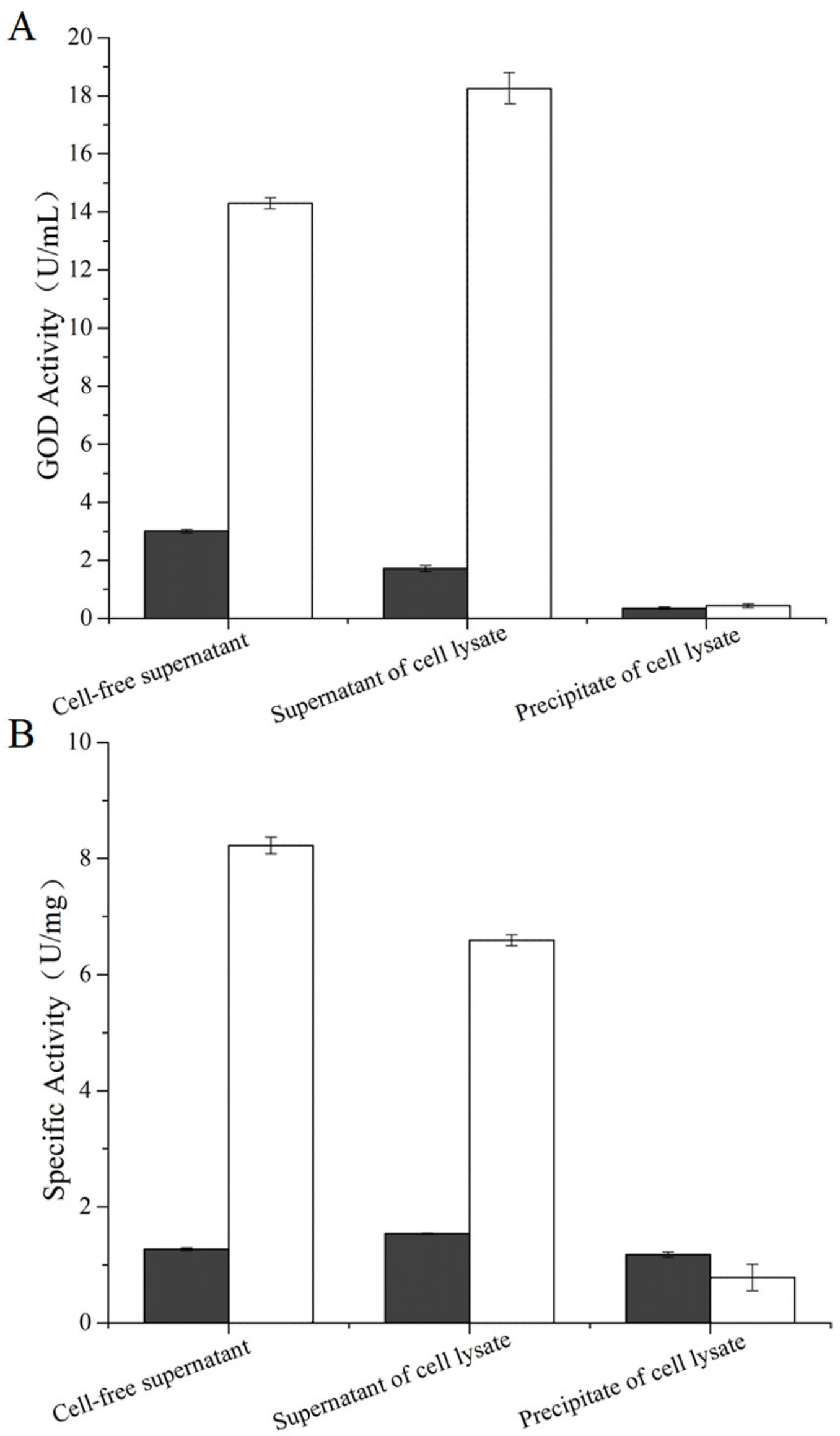


\section{Figure 3}

Fig. 3 Production of hydrogen peroxide by the GOD preparations.

Fig. 3 Production of hydrogen peroxide by the GOD preparations. Hydrogen peroxides produced by GOD from P. pastoris GS115-His-GOD 01 are in colorless columns, and in black columns from $P$. pastoris GS115-pPIC9K. Note: Cell-Free supernatant, the GOD from the supernatant after fermentation; Supernatant of cell lysate, the GOD from the supernatant of the cell lysate by ultrasonication; Precipitate of cell lysate, the GOD from the precipitation of cell lysate by ultrasonication.

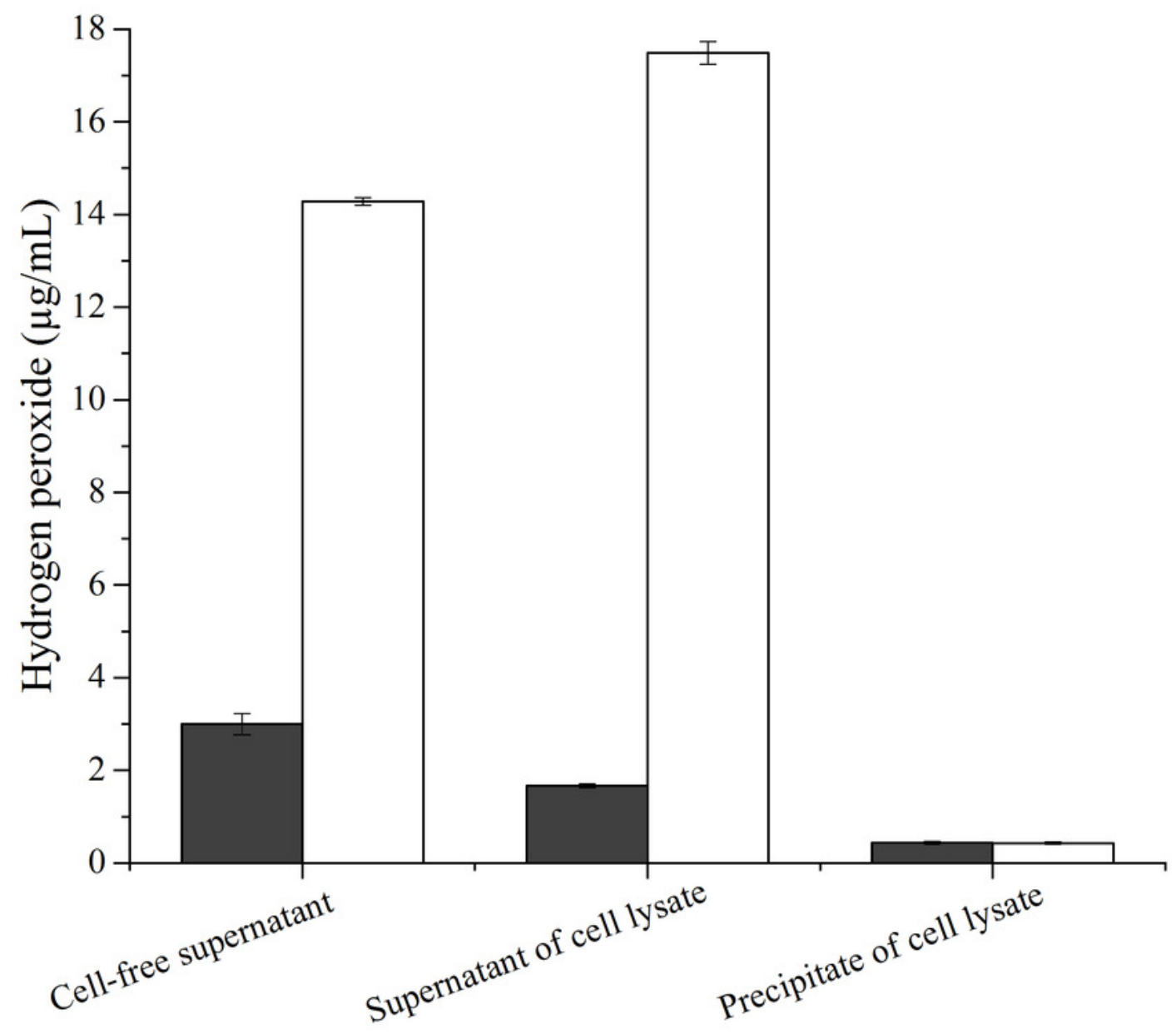




\section{Figure 4}

Fig. 4 Inhibition effects of the GOD preparations on growth of A.tumefaciens LBA4404 and $E$. coli DH5 $\alpha$ in liquid media.

Fig. 4 Inhibition effects of the GOD preparations on growth of A.tumefaciens LBA4404 and E. coli DH5 $\alpha$ in liquid media. A and B shows the inhibition effects of the GOD $(1.0 \mathrm{U} / \mathrm{mL})$ on growth of A.tumefaciens LBA4404 and E. coli DH5 $\alpha$ with the final concentrations of glucose were $1.0 \mathrm{mg} / \mathrm{mL}, 2.5 \mathrm{mg} / \mathrm{mL}, 5.0 \mathrm{mg} / \mathrm{mL}$, respectively. $C$ and $D$ displayed the inhibition effects of the GOD $(5.0 \mathrm{U} / \mathrm{mL})$ on growth of A.tumefaciens LBA4404 and E. coli DH5 $\alpha$ with the final concentrations of glucose were $1.0 \mathrm{mg} / \mathrm{mL}, 2.5 \mathrm{mg} / \mathrm{mL}, 5.0 \mathrm{mg} / \mathrm{mL}$, respectively. $E$ and $\mathrm{F}$ displayed the inhibition effects of the GOD $(10.0 \mathrm{U} / \mathrm{mL})$ on growth of A.tumefaciens LBA4404 and $E$. coli DH5 $\alpha$ with the final concentrations of glucose were $1.0 \mathrm{mg} / \mathrm{mL}, 2.5 \mathrm{mg} / \mathrm{mL}, 5.0$ $\mathrm{mg} / \mathrm{mL}$, respectively. 
A

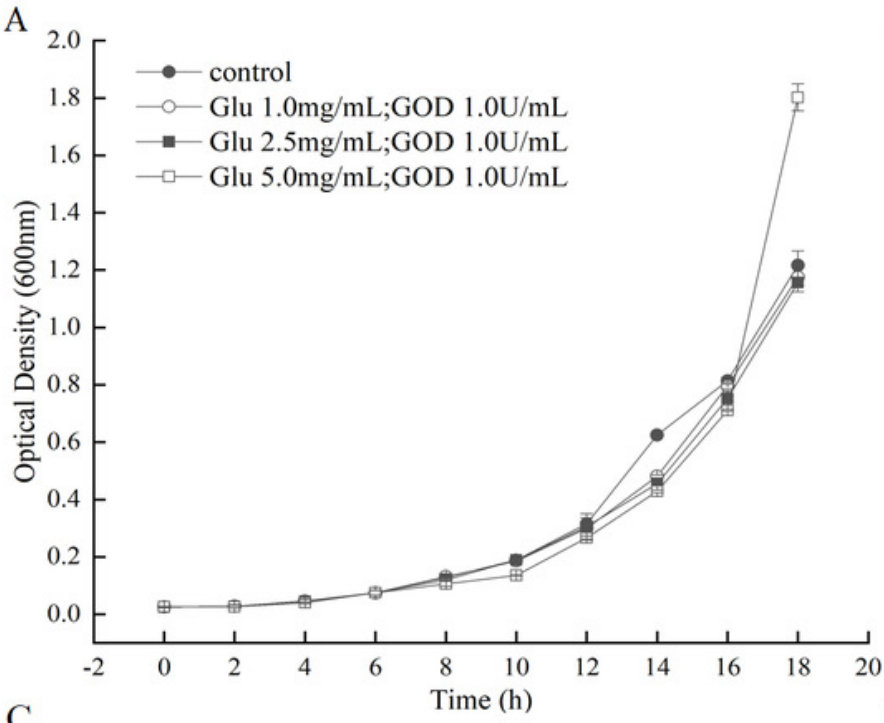

C

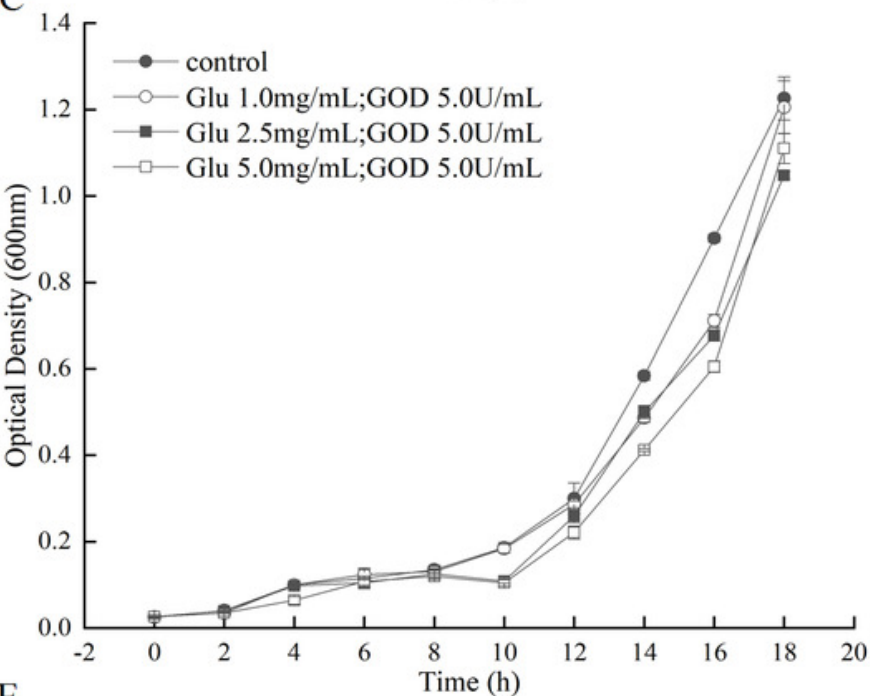

$\mathrm{E}$

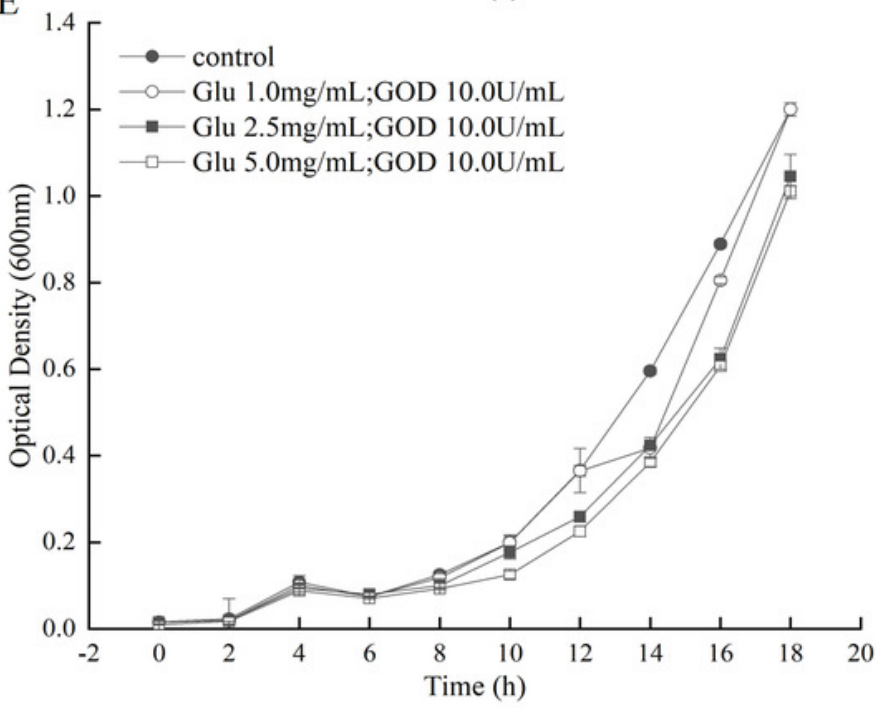

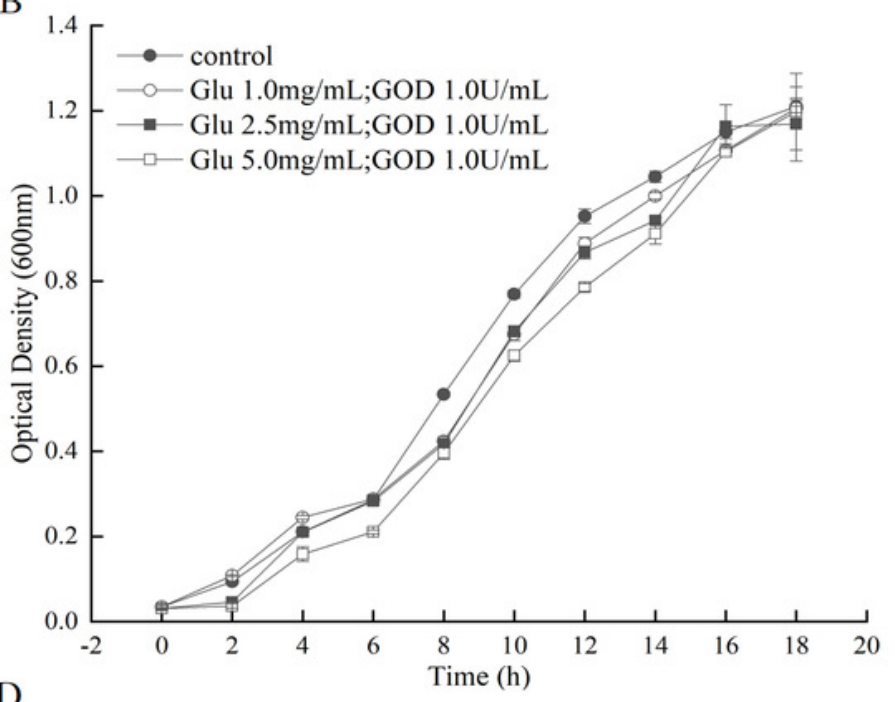

D

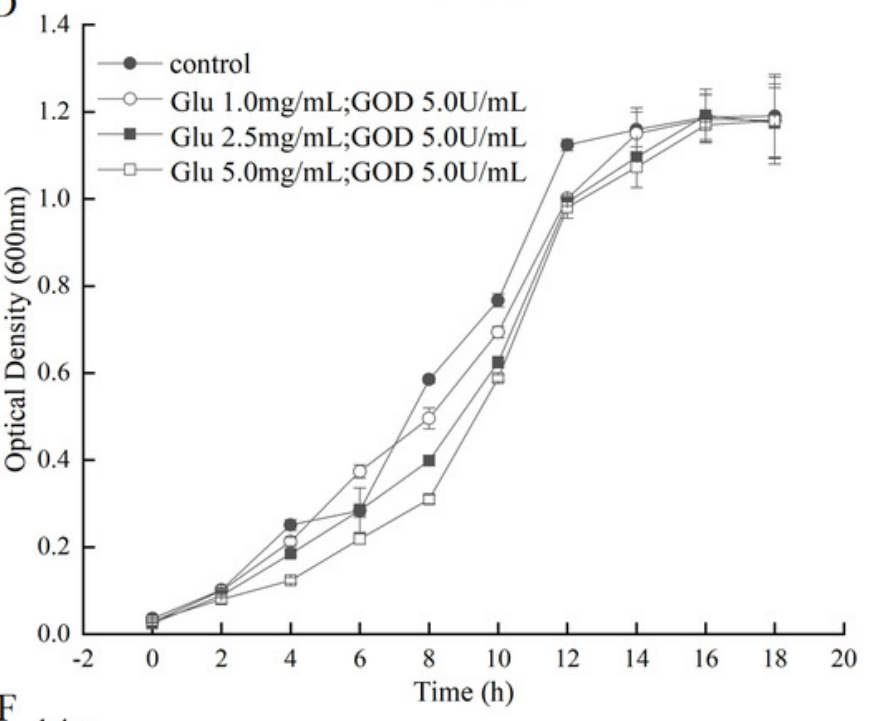

$\mathrm{F}$

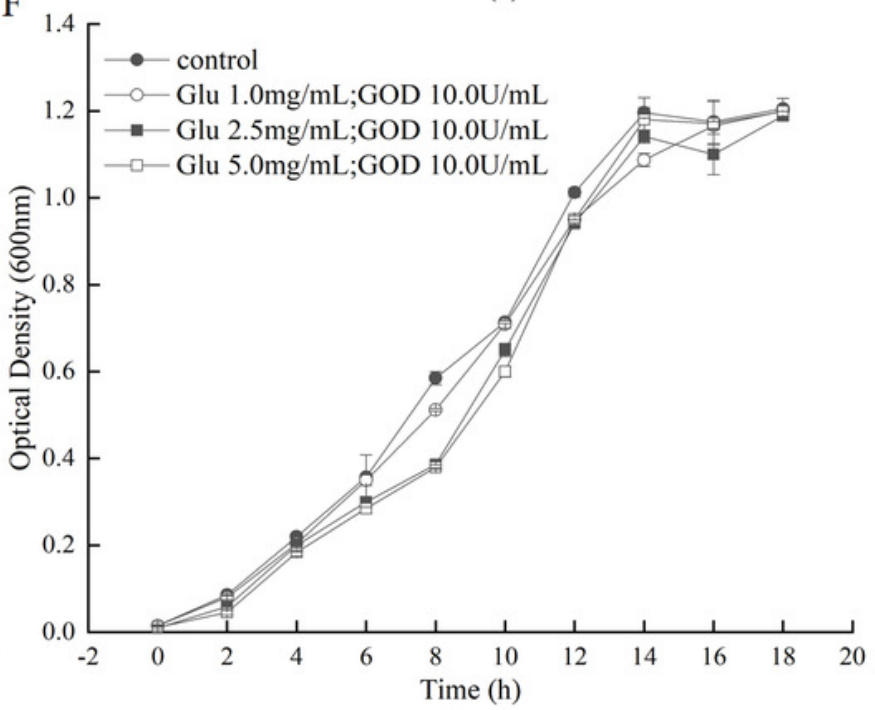




\section{Figure 5}

Fig. 5 Inhibition effects of the GOD preparations on growth of A.tumefaciens LBA4404 (A) and E. coli DH5a (B) in solid media.

Fig. 5 Inhibition effects of the GOD preparations on growth of A.tumefaciens LBA4404 (A) and E. coli DH5a (B) in solid media. (1) denotes the GOD preparations from the cell-free supernatant of $P$. pastoris GS115-His-GOD 01; (2) is the supernatant of cell-lysate of $P$. pastoris GS115-His-GOD 01 by ultrasonication; (3) is the precipitate of cell-lysate of $P$. pastoris GS115-His-GOD 01 by ultrasonication; (4) represents the negative control with the sterile water.
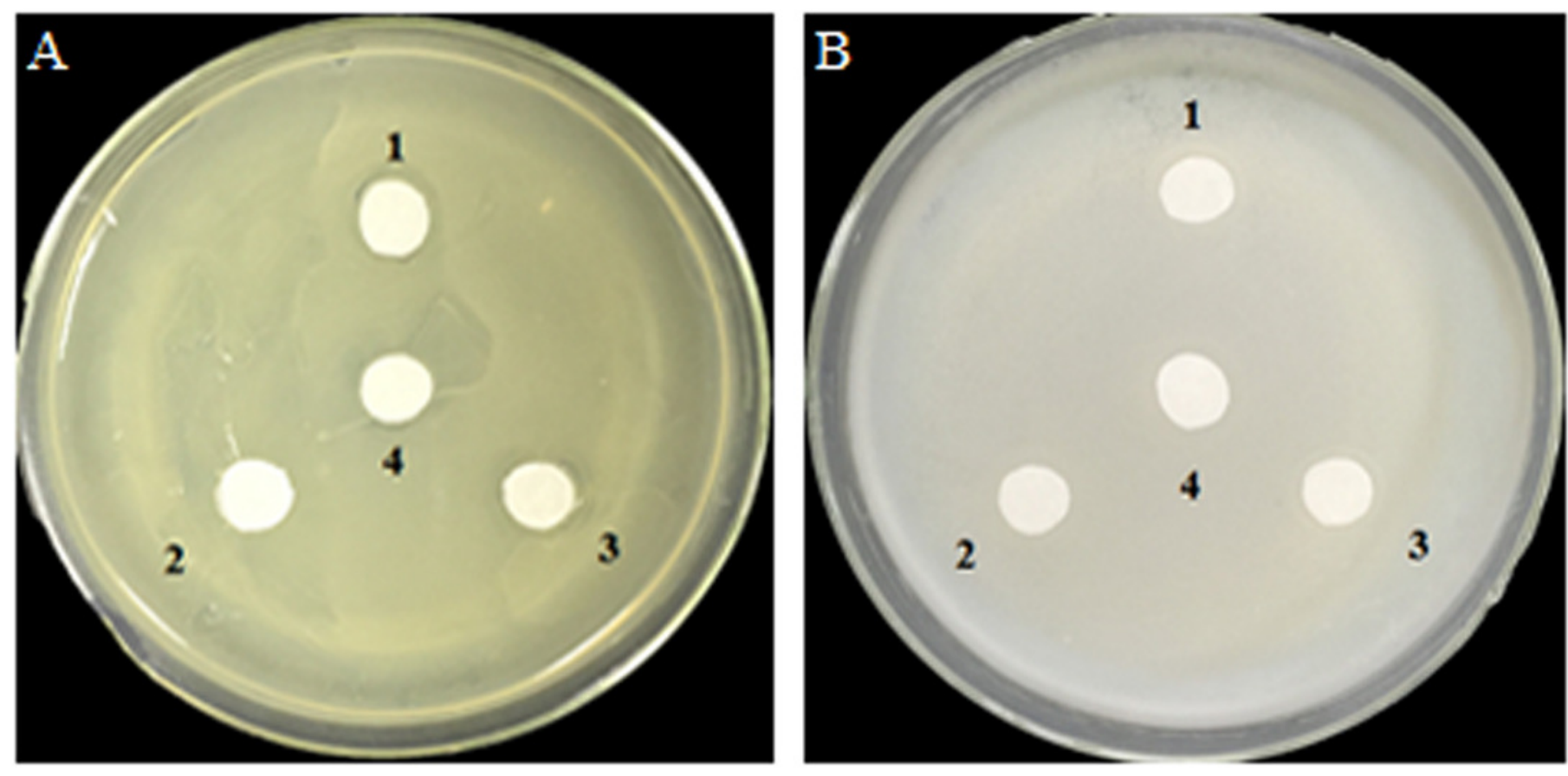


\section{Figure 6}

Fig. 6 Different concentrations of hydrogen peroxide solution effect on $A$. tumefaciens LBA4404 and E. coli DH5a on agar plates.

Fig. 6 Different concentrations of hydrogen peroxide solution effect on A. tumefaciens LBA4404 and E. coli DH5a on agar plates. A represents the inhibit effects of different concentrations of hydrogen peroxide solutions (Marked from number 1 and 15) on the growth of $A$. tumefaciens LBA4404; B represents the inhibit effects of different concentrations of hydrogen peroxide solutions (Marked from number 1 and 12) on the growth of $E$. coli DH5a.
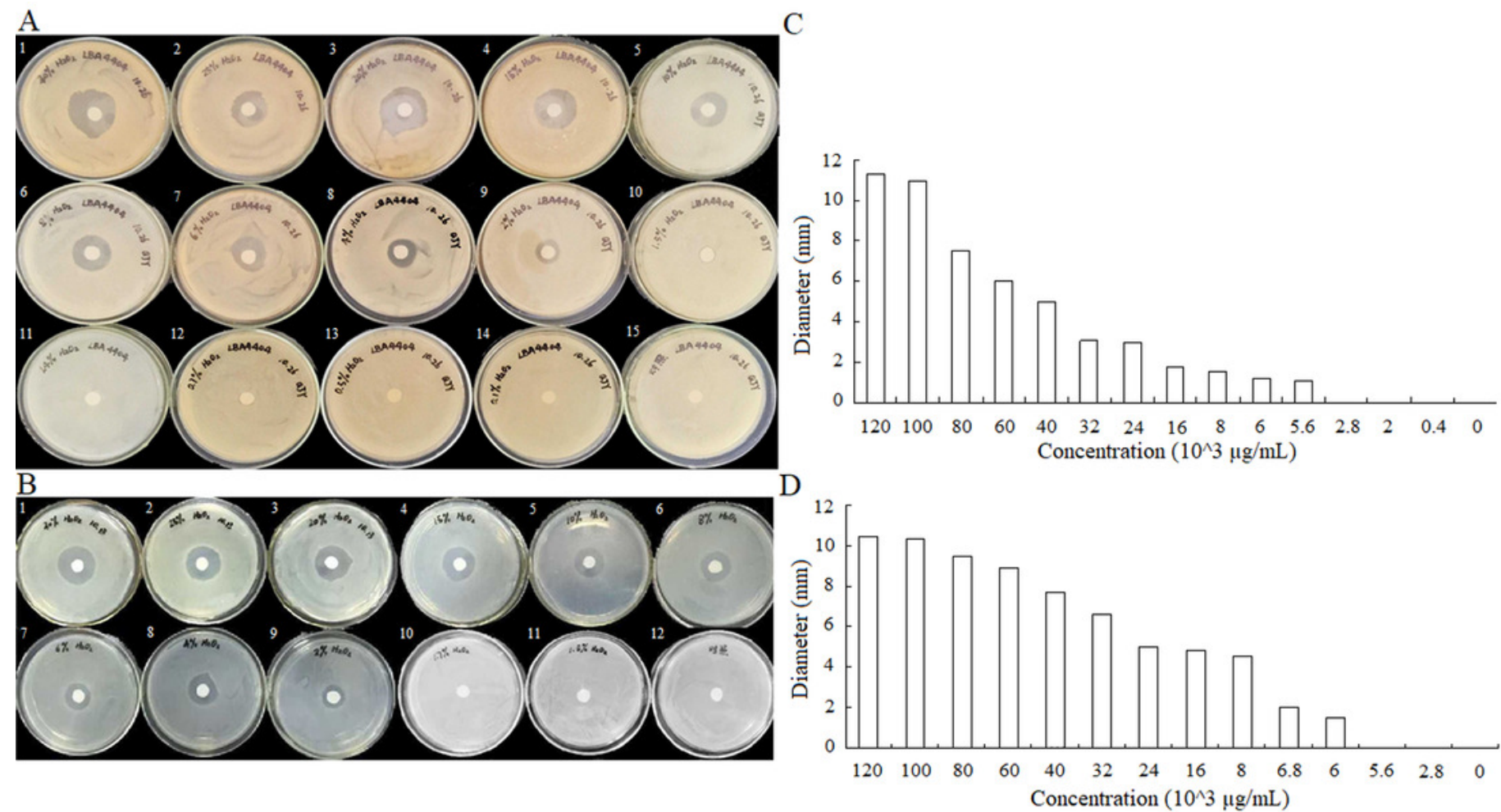